\title{
Comparative study of alternative biofuels on aircraft engine performance
}

\author{
Muhammad Hanafi Azami and Mark Savill
}

\begin{abstract}
Aviation industries are vulnerable to the energy crisis and simultaneously posed environmental concerns. Proposed engine technology advancements could reduce the environmental impact and energy consumption. Substituting the source of jet fuel from fossilbased fuel to biomass-based will help reduce emissions and minimize the energy crisis. The present paper addresses the analysis of aircraft engine performance in terms of thrust, fuel flow and specific fuel consumption (SFC) at different mixing ratio percentages $(20 \%, 40 \%$, $50 \%, 60 \%$ and $80 \%$ ) of alternative biofuel blends already used in flight test (Algae biofuel, Camelina biofuel and Jatropha biofuel) at different flight conditions. In-house computer software codes, PYTHIA \& TURBOMATCH were used for the analysis and modeling of a three-shaft high-bypass-ratio engine which is similar to RB211-524. The engine model was verified and validated with open literature found in the test program of Bio-Synthetic Paraffinic Kerosene in commercial aircraft. The results indicated that Lower Heating Value (LHV) had a significant influence on thrust, fuel flow, and SFC at every flight condition and at all mixing ratio percentages. Wide LHV differences between two fuels give a large variation on the engine performances. Blended Kerosene-Jatropha Biofuel and Kerosene-Camelina Biofuel showed an improvement on gross thrust, net thrust, reduction of fuel flow and SFC at every mixing ratio percentage and at different flight conditions. Moreover, the pure alternative of Jatropha Biofuel and Camelina Biofuel gave much better engine performances. This was not the case for the Kerosene-Algae blended biofuel. This study is a crucial step in understanding the influence of different blended alternative biofuels on the performance of aircraft engines.
\end{abstract}

Center for Propulsion, Cranfield University, U.K

Corresponding author:

Muhammad Hanafi Azami, Centre for Propulsion, Cranfield University,

MK43 0AL, United Kingdom.

Email:m.azami@cranfield.ac.uk 


\section{Keywords}

Alternative biofuels, engine performances, blended fuels, Algae biofuel, Camelina biofuel, Jatropha biofuel

\section{Introduction}

Currently, aviation industries addressed two vital issues which are the environmental crisis due to global warming and the energy crisis that leads to a constant rise in global oil prices which affects the domestic energy situations $(1,2)$. The primary motivations for the present work have ignited a desire for renewable and sustainable energy sources to have more secured fuel supplies(3). The International Energy Agency (IEA) has reported that the world will need $50 \%$ more energy in 2030 than it needs today(4), with the transportation sector becoming the second largest energy consuming sector after the industrial sector. Mostly, transportation sector sourced from fossil fuels consumed more than $90 \%$ of fossil fuel energy while a small amount is sourced from natural gas and renewable energy sources $(5,6)$. As the demand for energy increases, the conventional oil and natural gas reserves that can be commercially exploited will diminish after approximately 41.8 and 60.3 years, respectively(4).

Fortunately, there are promising alternatives to respond to the energy crisis and environmental concerns- in particular by changing the source of jet fuel from fossil-based to biomass-based. The International Air Transport Association aspires to use 6\% biofuel blends in aircraft by 2020 and several test flights have already been performed using blends of conventional jet fuel and bio-jet fuel from algae, Camelina, Jatropha and other plant-based feedstocks for both commercial airliners and military aircraft(7). Sustainability remains the main concern in order for biofuels to become the source of jet fuel; notably the ability for the biofuel to conserve ecological balance, productivity, biodiversity and natural resources. Payan et al. (8) have addressed environmental studies of alternative fuels and analyzed the relative greenhouse gas (GHG) emission reduction for biomass sources compare to conventional jet fuel based on fossil sources and its blend. The results are summarized in Table 1. 
Biofuel is defined as a fuel comprised of mono-alkyl esters of long-chain fatty acids derived from renewable resources that can be produced by a simple chemical process known as transesterification. It is a process where the triglycerides react with alcohols in the presence of a catalyst(9) using edible, non-edible, waste vegetable oils and animal fats produced by organisms $(3,4,10)$. Biofuel feedstocks are divided into four sources which are; edible oils, non-edible oils, animal fats and other sources. The available feedstocks are listed in Table 2.

Biofuel is compatible with diesel engines in its pure form or by blending it with petroleum diesel in a certain ratio(11) to improve the quality of ignition, the properties of fuel flow in cold temperature, and the stability of fuel (oxidation). This is because the quality of biofuel and the properties are highly dependent on the presence of fatty acid (FA), the size distribution of FA and the degree of unsaturation within these FA chains in the fuel blend $(3,4)$. Biofuel should have a low concentration of long-chain saturated Fatty Acid Methyl Esters (FAME) for a good low-temperature performance and for good oxidative stability(3).

Table 1. GHG Emission reduction with different feedstocks relative to jet fuel (8)

\begin{tabular}{|c|c|}
\hline Feedstocks & GHG Emission Reduction (\%) \\
\hline Corn Stover & 55 \\
\hline Sweet Sorghum & 133 \\
\hline Canola & 44 \\
\hline Camelina & 86 \\
\hline Jatropha & 42 \\
\hline Waste Fat & 87 \\
\hline Wood Residues & 148 \\
\hline Miscanthus & 72 \\
\hline Switchgrass & 63 \\
\hline Algae & 124 \\
\hline
\end{tabular}


Table 2. Source of feedstocks(5)

\begin{tabular}{|c|c|c|c|c|}
\hline Edible oils & \multicolumn{2}{|c|}{ Non-edible oils } & \multirow{2}{*}{$\begin{array}{l}\text { Animal fats } \\
\text { Pork lard }\end{array}$} & \multirow{2}{*}{$\begin{array}{l}\text { Other sources } \\
\text { Bacteria }\end{array}$} \\
\hline Soybeans & Salmon oil & Coffee ground & & \\
\hline Rapeseed & Mahua & Karanja & Beef tallow & Algae \\
\hline Safflower & Pongamia & Camelina & Poultry fat & Microalgae \\
\hline Rice bran oil & Cumaru & Neem & Fish oil & Tarpenes \\
\hline Barley & Tall & Nagchampa & Chicken fat & Poplar \\
\hline Sesame & Jojoba & Moringa & & Switchgrass \\
\hline Groundnut & Cotton seed & Rubber seed & & Miscanthus \\
\hline Sorghum & Tobacco seed & Passion seed & & Latexes \\
\hline Wheat & \multicolumn{2}{|c|}{ Abutilon muticum } & & Fungi \\
\hline Corn & \multicolumn{2}{|l|}{ Jatropha curcas } & & Waste cooking oil \\
\hline Coconut & \multicolumn{2}{|c|}{ Croton megalocarpus } & & \\
\hline Canola & \multicolumn{2}{|c|}{ Aleurites moluccana } & & \\
\hline Peanut & \multicolumn{2}{|l|}{ Pachira glabra } & & \\
\hline Palm \& palm kernel & \multicolumn{2}{|c|}{ Terminalia belerica } & & \\
\hline Sunflower & \multicolumn{2}{|c|}{ Cynara cardunculus } & & \\
\hline
\end{tabular}

There are two types of biofuels that have been certified for aviation use and when blended with at least 50\% with conventional kerosene: (1) the Fischer-Tropsch (F-T) hydroprocessed Synthesized Paraffinic Kerosene (SPK) and (2) the synthesized paraffinic kerosene from Hydroprocessed Esters and Fatty Acids (HEFA)(8). Three types of refining processes to convert bio-derived feedstock sources into bio-jet fuels are; (1) Fischer-Tropsch (F-T) process, (2) Alcohol-To-Jet (ATJ) process, and (3) Fast pyrolysis (HEFA) process. In the present context, it is worth highlighting that there have been three successful biofuel flights of commercial aircraft, which are Air New Zealand's Boeing 747-400 in 2008, Continental Airlines Boeing 737-800 and Japan Airline Boeing 747-300 in 2009. These flights used bioSPK blends of up to $50 \%$ with conventional fuel and found no abnormal impacts for different engine operations(12). 


\section{Present work}

Since Payan et al. (8) have described how the biomass-based fuel could contribute to GHG reduction and addressed the environmental concern at the same time, the focus of this present study is to investigate the effect of blended biofuels on aircraft engine performance especially on gross thrust, fuel flow and specific fuel consumption at different flight conditions and at different blended mixing ratio percentages. This is equally important so that the engine performances are not undermined as well. Three biofuels namely Algae Biofuel, Jatropha Biofuel, and Camelina Biofuel are evaluated as pure fuel and are blended with kerosene $\left(C_{12} H_{24}\right)$ at $20 \%, 40 \%, 50 \%, 60 \%$ and $80 \%$. These biofuels are chosen because of the previous success in the test flight program and the fuel properties are available in the published literature as listed in Table 3. A model of a three-shaft high-bypass-ratio engine RB211-524 was used throughout the analysis using available engine parameters for verification. Validation was done for an RB211 variant and comparisons with the work of Rahmes et al (12) were also further conducted to examine the effects of different percentages of blended fuel mixing ratios.

Our in-house computer software was used for the computational analysis. The PYTHIA program has the ability to design and calculate various gas turbine engines for both design and off-design points using a modified Newton-Raphson convergence technique in the zerodimensional steady-state model(13). Moreover, it can serve as a diagnostic tool for deterioration analysis and allows map scaling for off-design conditions. PYTHIA is integrated with our TURBOMATCH performance evaluation program. PYTHIA calls for TURBOMATCH program which is coded in FORTRAN to iterate the mass and energy balance for each engine component. PYTHIA is considered to be user-friendly(14) and has a novel interface for engine component selection. The capability of PYTHIA has been tested and validated for many years $(15,16)$ ranging from industrial gas turbines to aero-gas turbines. The latest version of PYTHIA has the capability to change the fuel type and to vary the blended mixing ratio percentage while maintaining the same engine design as for the conventional kerosene case. This is essential to evaluate fit-for-purpose fuels for real engines at various operating points. The present work may thus serve as an extension of Mazlan et al. (14) work using an 
earlier version of PYTHIA which could only provide strict comparisons for different pure fuels for single design conditions only. These latest findings not only support earlier findings but also go beyond them due to more capabilities have been put into a new version of PYTHIA such as analyzing more alternative fuels options at different off-design conditions.

Table 3. Biofuel properties.

\begin{tabular}{|c|c|c|c|}
\hline & Algae & Jatropha & Camelina \\
\hline Density $\left(\mathrm{kg} / \mathrm{m}^{3}\right)$ & 883.6 & $864-880$ & - \\
\hline Cetane Number & $85-92$ & $46-55$ & 50.4 \\
\hline $\begin{array}{l}\text { Viscosity } \\
\left(\mathrm{mm}^{2} / \mathrm{s} \text { at } 40^{\circ} \mathrm{C}\right)\end{array}$ & 4.73 & $3.7-5.8$ & 3.80 \\
\hline Pour Point $\left({ }^{\circ} \mathrm{C}\right)$ & $-21--24$ & 5 & -7 \\
\hline Flash Point $\left({ }^{\circ} \mathrm{C}\right)$ & 179 & $163-238$ & 136 \\
\hline $\begin{array}{l}\text { Heating Value } \\
(\mathrm{MJ} / \mathrm{kg})\end{array}$ & 43 & 44.4 & 44 \\
\hline CFPP $\left({ }^{\circ} \mathrm{C}\right)$ & - & -1.2 & -3 \\
\hline Acid Value (mg/KOH) & 0.37 & 0.34 & \\
\hline Cloud Point $\left({ }^{\circ} \mathrm{C}\right)$ & 7 & 5 & 3 \\
\hline Oxidation Stability(h) & 6.76 & 5.0 & - \\
\hline Iodine Value $\left(I_{2} / 100 \mathrm{~g}\right)$ & 97.12 & 109.5 & 152.8 \\
\hline $\begin{array}{l}\text { Sulphur Content } \\
\text { (ppm) }\end{array}$ & 8.1 & 12.9 & - \\
\hline $\begin{array}{l}\text { Specific Gravity } \\
(\mathrm{g} / \mathrm{ml})\end{array}$ & 1.02 & 0.876 & 0.882 \\
\hline $\begin{array}{l}\text { Molecular Formula } \\
\text { References }\end{array}$ & $\begin{array}{c}\boldsymbol{C}_{\mathbf{1 2}} \mathrm{H}_{\mathbf{1 9}} \mathrm{O}_{\mathbf{3}} \mathbf{N} \\
(17-21)\end{array}$ & $\begin{array}{l}\mathrm{C}_{\mathbf{1 2}} \mathrm{H}_{\mathbf{2 6}} \\
(3,4,22)\end{array}$ & $\begin{array}{c}\mathrm{C}_{\mathbf{1 2}} \mathrm{H}_{25.4} \\
\text { (3) }\end{array}$ \\
\hline
\end{tabular}

\section{Methods}

The configuration of the RB211-524 engine was specified in PYTHIA using available library data and default settings configurations. The model engine configurations are illustrated in Figure 1. At design point, kerosene fuel was selected. Each component of the engine model is described in terms of a 'brick' which has its functionality. The ambient conditions (input) were ascribed according to the intended flight conditions such as altitude, flight speed, mass flow, pressure recovery, pressure deviation and relative humidity in the INTAKE brick. For compressors, the first compressor has the maximum pressure ratio of 2.0 with $-10^{\circ}$ stator angle. The subsequent high pressure (HP) compressors have the maximum pressure ratio of 11.0 with $-10^{\circ}$ stator angles. However, only the HP compressors are assumed to have bleeding air. The PREMAS brick is used to calculate the outlet conditions from components such as a splitter, bleed, bypass duct or jet pipe, by given the absolute relate changes of mass flow and total pressure. There is no water flow introduced to the burner. Meanwhile, 
MIXEES brick is used to calculate the outlet conditions result from the constant-area mixing of two flows with no allowance for total pressure loss while MIXFUL brick data is used after TURBINE brick data for calculating outlet conditions from the constant-area mixing flows with full allowance for total pressure change resulting from momentum balance. All turbines are set to have identical maximum enthalpy drop ratio of 0.04 and turbine inlet temperature (TIT) of $1580 \mathrm{~K}$. Moreover, these turbines have $-10^{\circ}$ angle positions and are choked at low speed. A convergent nozzle is selected in the NOZZLE brick. Results for the engine parameters and performance for the baseline fuel are tabulated in Table 4 .
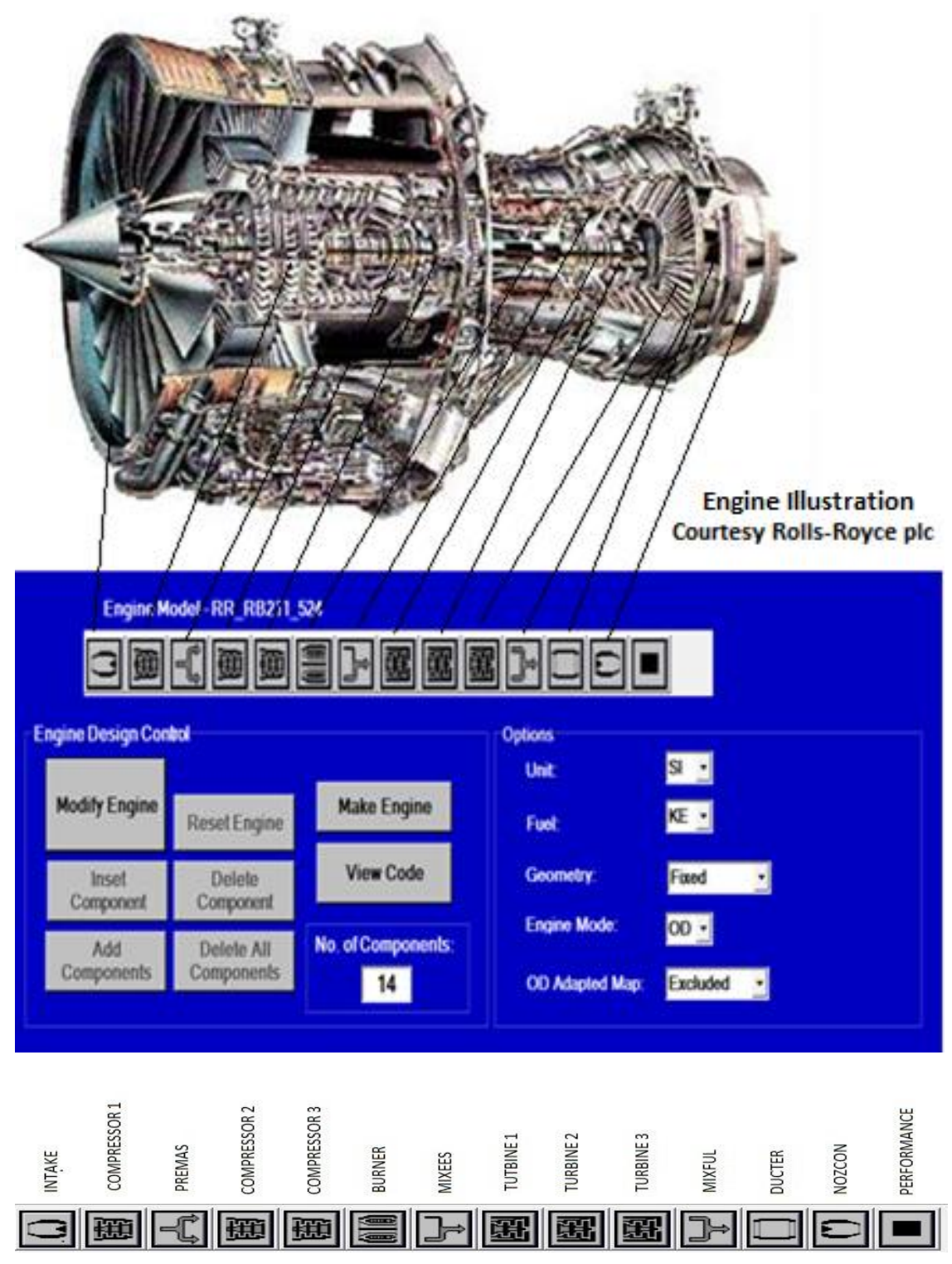

Figure 1. PYTHIA engine model schematic diagram. 
The flowchart of the PYTHIA process is illustrated in Figure 2. It begins with the user defining inputs as previously mentioned in PYTHIA. TURBOMATCH is called for the iterations in mass (equation (1)) and energy (equation (2)) balance relation. Equation (1) and equation (2) should be satisfied between successive components. New initial guess for pressure ratio, temperature (burner) and rotational speed must be made before iteration process. TURBOMATCH is coded using FORTRAN. Compressor and turbine maps were needed for mass balance iteration process. NASA Chemical Equilibrium Analysis (CEA) is applied for the evaluation of thermochemical fuel properties such as the correlation of enthalpy, flame temperature, specific heat and molecular formula to the function of temperature. These correlations are stored in the TURBOMATCH library data. The iteration process will require several initial guess values before it converges. Lastly, the data were executed and imported to the excel spreadsheet for data analysis.
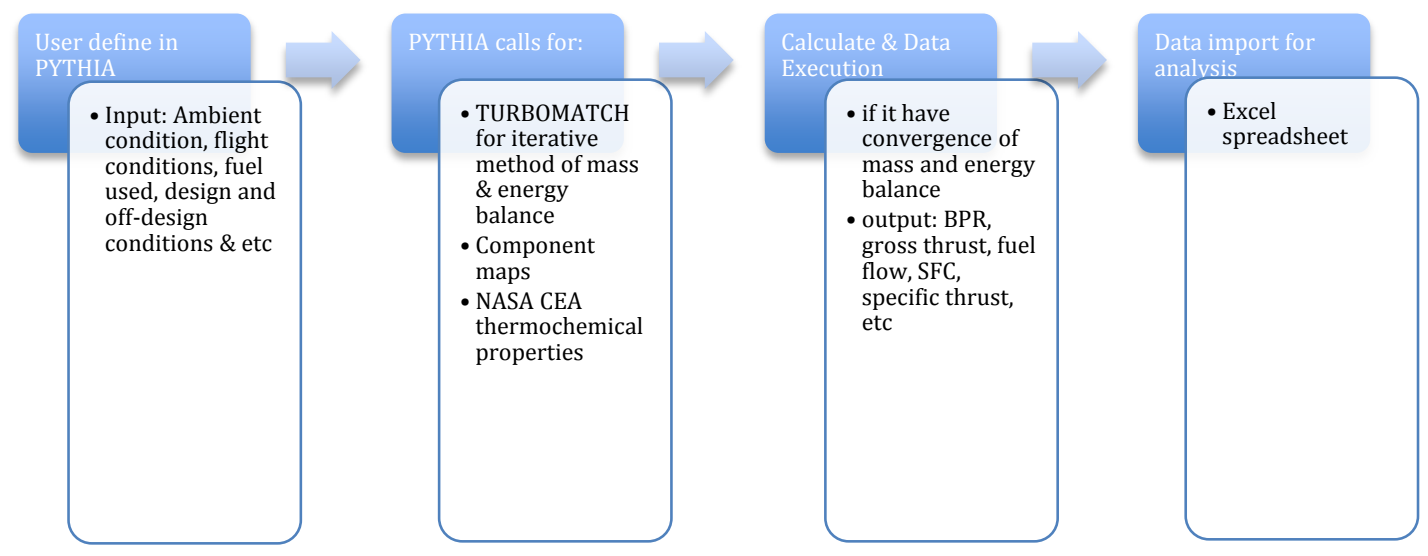

Figure 2. PYTHIA data process flowchart.

$$
\frac{W_{n} \sqrt{T_{n}}}{P_{n}}=\frac{W_{n+1} \sqrt{T_{n+1}}}{P_{n+1}}
$$

Turbine Work $(T W)=$ Compressor $W$ ork $(C W)$ 
Table 4. Engine parameters and performance for baseline fuel.

INTAKE

\begin{tabular}{lc}
\hline Altitude (m) & 10588 \\
Flight Mach Number & 0.84 \\
Mass flow intake (kg/s) & 670 \\
Relative Humidity (\%) & 60 \\
Momentum Drag (kN) & 189.72 \\
\hline
\end{tabular}

COMPRESSORS

\begin{tabular}{lccc}
\hline & 1 & 2 & 3 \\
$\mathbf{Z}$ & 0.7 & 0.8 & 0.8 \\
PR & 1.80 & 4.06 & 4.06 \\
ETA & 0.895 & 0.89 & 0.885 \\
WA $(\mathbf{k g} / \mathbf{s})$ & 670 & 126.4 & 126.4 \\
P total (atm) & 1.96 & 1.96 & 7.96 \\
\hline
\end{tabular}

COMBUSTORS

\begin{tabular}{lc}
\hline ETA & 0.99 \\
Pressure Drop (atm) & 1.29 \\
Fuel Flow (kg/s) & 2.18 \\
LHV (MJ/ kg fuel) & 43.12 \\
P total (atm) & 31.04 \\
FAR & 0.02 \\
\hline
\end{tabular}

TURBINES

\begin{tabular}{lccc}
\hline & 1 & 2 & 3 \\
ETA & 0.91 & 0.92 & 0.92 \\
T total (K) & 1580 & 1499 & 1240 \\
P total (atm) & 31.04 & 31.04 & 12.44 \\
WA (kg/s) & 112.18 & 128.61 & 128.61 \\
\hline
\end{tabular}

NOZZLE

\begin{tabular}{lc}
\hline Area $\left(\mathbf{m}^{2}\right)$ & 2.25 \\
Exit Velocity $(\mathbf{m} / \mathbf{s})$ & 394.0 \\
Nozzle Coefficient & 0.98 \\
T total $(\mathbf{K})$ & 464.39 \\
$\mathbf{P}$ total $(\mathbf{a t m})$ & 1.58 \\
\hline
\end{tabular}

ENGINE PERFORMANCES

\begin{tabular}{lc}
\hline BPR & 4.3 \\
Gross Thrust (kN) & 293.38 \\
Fuel Flow (kg/s) & 2.18 \\
SFC (kg/N.s) & 21.07 \\
Specific Thrust (N/kg.s) & 154.71 \\
\hline
\end{tabular}

\subsection{Varying flight conditions}

To describe the differences in flight conditions, the INTAKE block diagram is adjusted accordingly in the off-design performance analysis. This is done by varying the flight speed and the altitude. PYTHIA is executed at the off-design points for different flight conditions. 


\subsection{Varying mixing ratio percentages}

These were conducted by repeating the previously described procedures but an exception was made for the BURNER brick. Three design parameters were adjusted accordingly. The three parameters (user input) are the fuel combination, second fuel type, and fuel-mixing rate. These parameters are user input. Fuel combination represents the condition of how the fuel is mixed. There are three options for selection; keeping the original fuel, replacing the original fuel, and mixing the fuel. The second type of fuel is defined as the type of second fuel used. Fuel-mixing rate corresponds to the blending mixing ratio percentages from $0-1$, where 1 represents the pure second-type fuel.

\section{Results and discussion}

\subsection{Influence of blended fuel on Lower Heating Value (LHV)}

Thermochemical properties such as LHV are major factors that influence the performance of aircraft engines. The blending ratio has a significant effect on LHV which thus affects the engine performance. Calorific value is the measure of heat energy content of a fuel. A higher calorific value of fuel is desired because it releases higher heat and consequently improves engine performance during combustion(4). Lower (LHV) and higher (HHV) heating values are measures of a fuel heat of combustion with the difference between them being the water heat of vaporization(22).

Figure 3 shows LHV variation at different mixing ratio percentages of biofuels with kerosene. $\mathrm{KE}+\mathrm{BJ}$ has higher $\mathrm{LHV}$ and followed by $\mathrm{KE}+\mathrm{BC}$. While $\mathrm{KE}+\mathrm{AG}$ has lower $\mathrm{LHV}$ as compared to pure KE fuel. As the mixing ratio increases towards pure blends of alternative fuels, the LHV differences become more severe. LHV results indicate up to $2.7 \%$ increase for the $\mathrm{KE}+\mathrm{BJ}$ combination and $2.03 \%$ increase for the $\mathrm{KE}+\mathrm{BC}$ as mixing ratio increases to a pure form. Moreover, $\mathrm{KE}+\mathrm{BJ}$ blended fuel has higher $\mathrm{LHV}$ compared to $\mathrm{KE}+\mathrm{BC}$ at every mixing ratio. However, $K E+A G$ fuel showed a reduction in $L H V$ as the mixing ratio increased towards unity. 


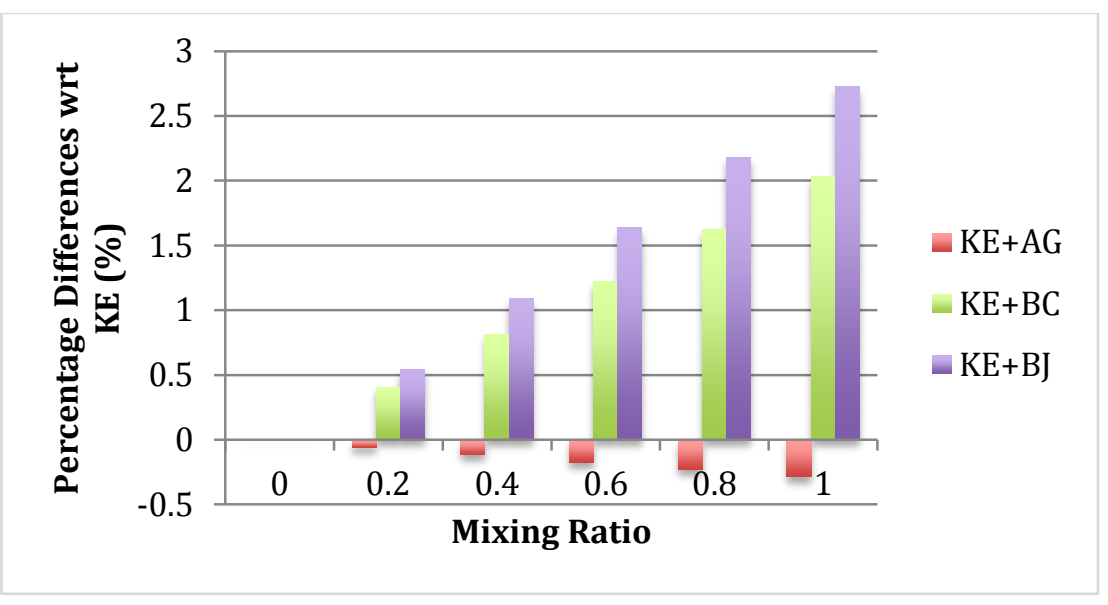

Figure 3. LHV percentage difference with respect to pure kerosene (KE) at different mixing ratios.

\subsection{Influence of $50 \%$ blended fuel on aircraft engine performance}

The blending of biofuels with conventional jet fuel is necessary to meet the requirement standard of current aviation fuels specifications. 50\% blended fuels are commonly used for flight testing as it represents a feasible approval within the existing specifications. Two different flight conditions; take-off and climbing were chosen for the analysis. Kerosene fuel is set as a baseline for comparison. Prior to the analysis, the engine model developed in PYTHIA was validated by comparing with the experimental works previously carried out by Rahmes et al (12) who conducted an off-wing engine ground test of an RB211-524 fueled with $50 \%$ Jatropha / 50\% Jet-A on a Boeing 747-400 of the Air New Zealand airline. $1.07 \%$ lower fuel flow was observed on the engine in the test-flight while our engine model has resulted a $1.11 \%$ reduction which is comparable using the same power setting at ground condition.

\subsubsection{Take off Condition}

At takeoff condition, the aircraft is accelerated to a takeoff velocity. The performance parameters for take-off condition are illustrated in Figure 4 - Figure 6. The line graphs in the primary axis represent the variation of performance parameters while the column graphs in the secondary axis represent the percentage differences with respect to the baseline. The variations of gross thrust for the alternative fuels are comparable with baseline fuel as illustrated in Figure 4. It shows very slight differences in gross thrust performance. However, 
the positive percentage indicates an increment in gross thrust at higher speeds. $50 \%$ of $\mathrm{KE}+\mathrm{BJ}$ blended biofuel has a larger percentage increment in gross thrust at every flight speed as compared to $50 \%$ of $\mathrm{KE}+\mathrm{BC}$ and $\mathrm{KE}+\mathrm{AG}$. This indicates that $50 \%$ of $\mathrm{KE}+\mathrm{BJ}$ blended biofuel can increase the gross thrust up to $0.22 \%$ and that $50 \%$ of $\mathrm{KE}+\mathrm{BC}$ can increase it by $0.19 \%$ at 0.3 Mach number. Meanwhile, $50 \%$ of $\mathrm{KE}+\mathrm{AG}$ blended biofuel has almost no significant difference in gross thrust compared to the baseline.

Fuel flow has a positive variation at every flight speed for all fuels (Figure 5) and it increases more rapidly after 0.1 Mach number. However, there are more significant differences between every fuel. Only $50 \%$ of KE+AG blended biofuel has a higher fuel flow than the baseline fuel. Meanwhile, $50 \%$ of KE+BJ blended biofuel has the lowest fuel flow. $50 \%$ of KE+BJ and $\mathrm{KE}+\mathrm{BC}$ blended biofuels showed some reductions in fuel flow (negative values). $50 \%$ of KE+AG blended biofuel appeared to have a nearly constant fuel flow percentage difference at every flight speed. These percentage trends seem to indicate that $50 \%$ of $K E+B J$ and $K E+B C$ blended biofuels give high reductions in fuel flow at low speeds.

Figure 6 displays a positive linear variation of SFC of the blended fuels at different flight speeds. The $50 \%$ of $\mathrm{KE}+\mathrm{BJ}$ and $50 \%$ of $\mathrm{KE}+\mathrm{BC}$ blended biofuels have a much lower SFC as compared to the baseline fuel while $50 \%$ of $\mathrm{KE}+\mathrm{AG}$ blended biofuel is almost equivalent with the baseline fuel. Nevertheless, the trends are slightly different with the fuel flow. The percentage difference of SFC is much higher at high Mach numbers for both $50 \%$ of KE+BJ and $\mathrm{KE}+\mathrm{BC}$ blended biofuels. As expected, the SFC is correlated to the fuel flow. At a higher Mach number, both of these parameters demonstrate an increase. Although the fuel flow percentage differences are reduced at higher Mach numbers, the SFC showed the opposite effect. Despite the fact that the SFC is increasing at a high Mach number, it actually provides more reduction in SFC when it is compared to the baseline fuel. These revealed the influence of LHV of these fuels where fuels having higher LHV require more heat for burning, thus, more fuel flow. However, using simplified SFC relations with LHV, it appears that LHV is inversely proportional with SFC as in equation (3):

$$
\mathrm{SFC}=\frac{v_{a} \cdot 3600}{\eta_{P} \eta_{T} L H V}
$$


Where $v_{a}, \eta_{P}$, and $\eta_{T}$ are flight velocity, propulsive efficiency, and thermodynamic efficiency.

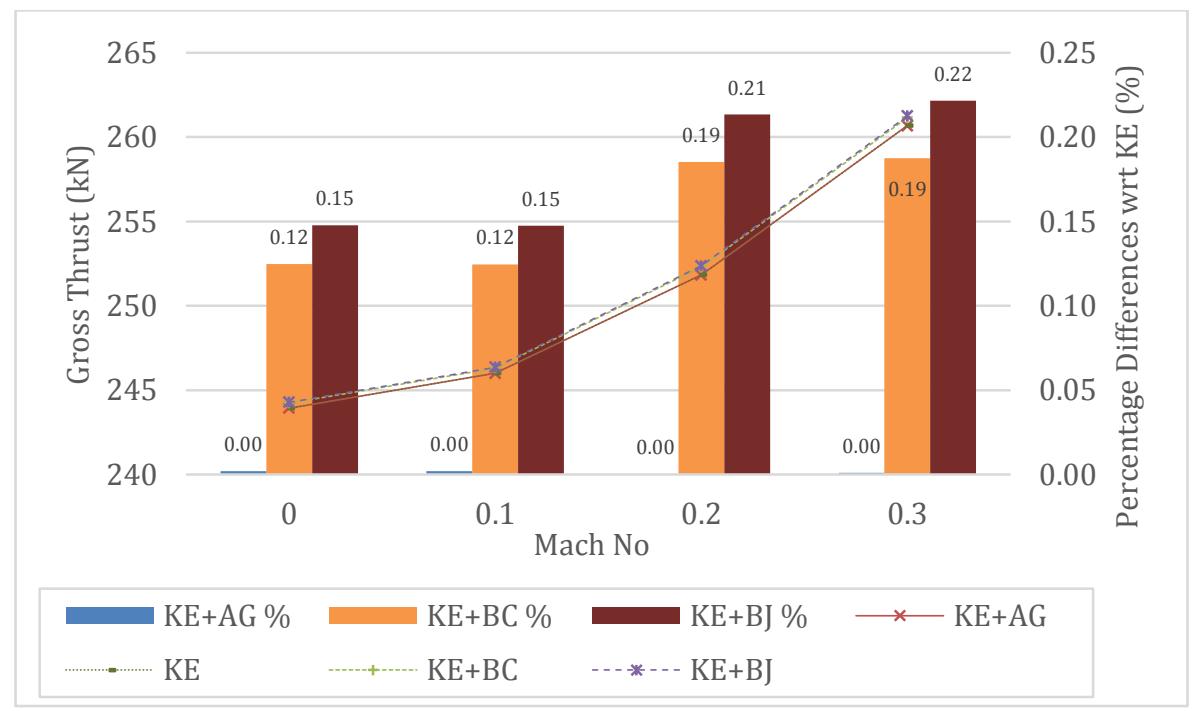

Figure 4. Variation of gross thrust at different Mach numbers.

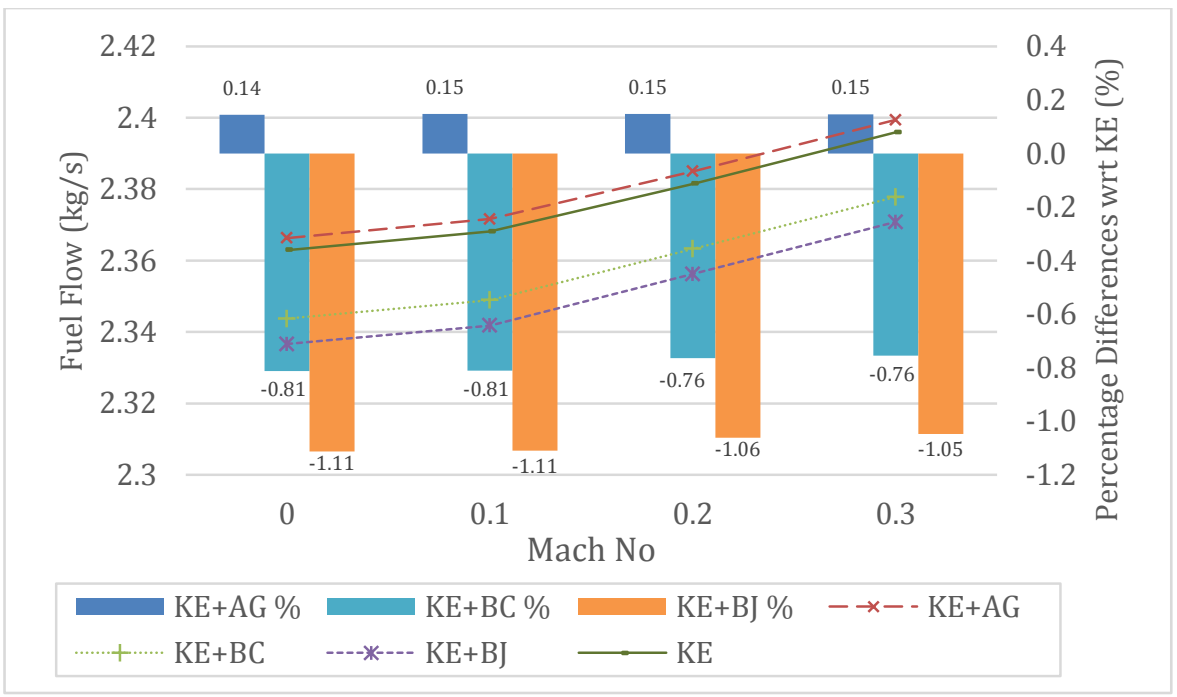

Figure 5. Variation of fuel flow at different Mach numbers. 


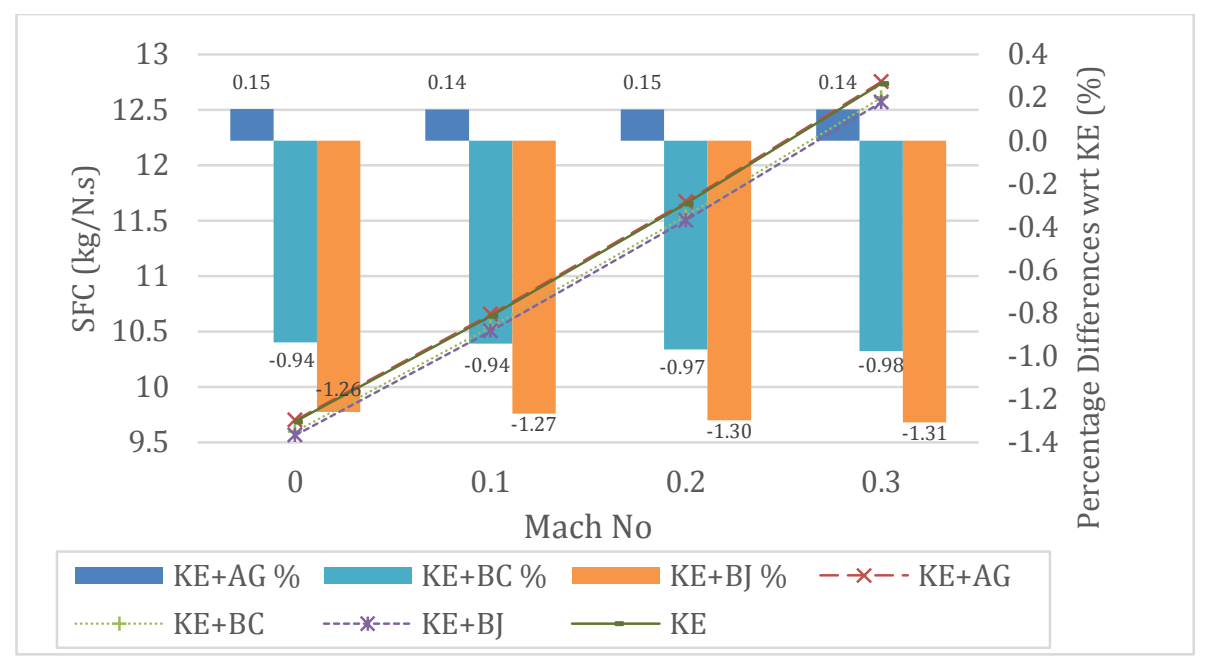

Figure 6. Variation of SFC at different Mach numbers.

\subsubsection{Climbing Condition}

Climbing condition is conducted to analyze the effect of the blended biofuels performances at different altitudes while keeping the flight speed constant at an average of 240 knots $(0.36 \mathrm{M})$. Both gross thrust and net thrust display negative and undistinguishable trends in all fuels as shown in Figure 7. Therefore, Figure 8 is plotted to visualize the small changes in these fuels with respect to the baseline fuel. $50 \%$ of $\mathrm{KE}+\mathrm{AG}$ blended biofuel show no differences in gross and net thrusts compared to the baseline fuel. Conversely, both $50 \%$ of $\mathrm{KE}+\mathrm{BJ}$ and $\mathrm{KE}+\mathrm{BC}$ blended biofuels illustrate a slight improvement in gross and net thrusts. Similarly, $50 \%$ of $\mathrm{KE}+\mathrm{BJ}$ blended biofuel has a much higher change in both gross and net thrusts.

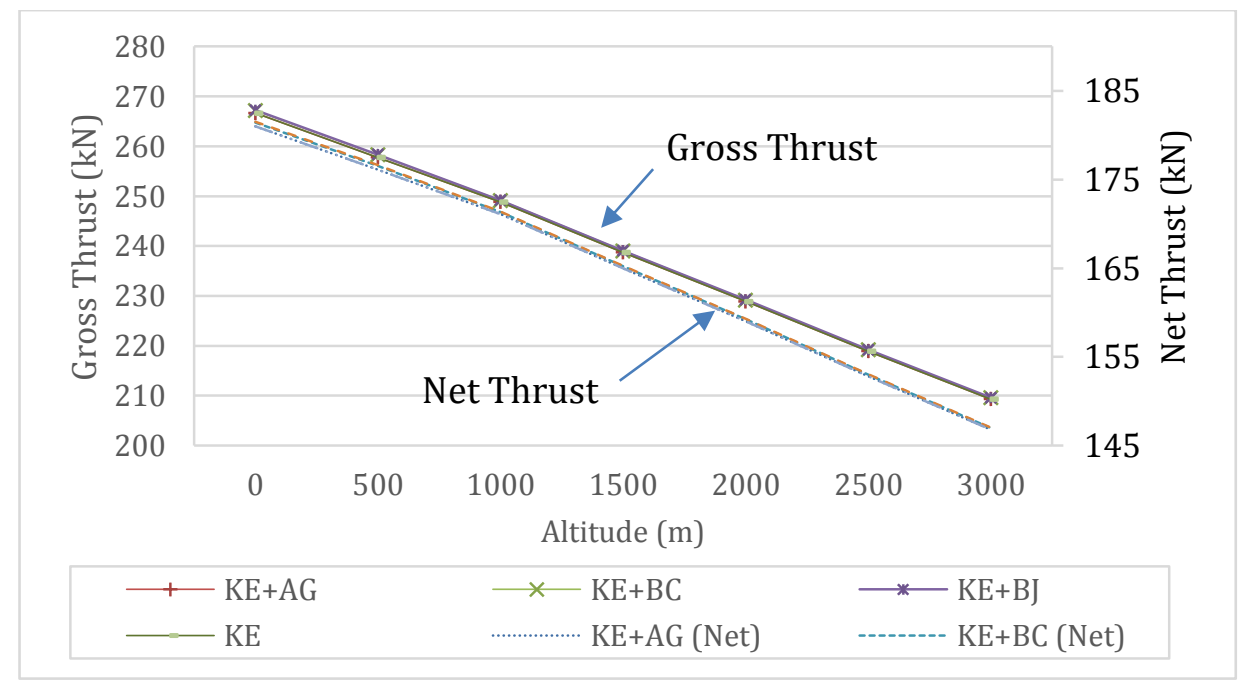

Figure 7. Variation of gross and net thrusts at different altitudes. 


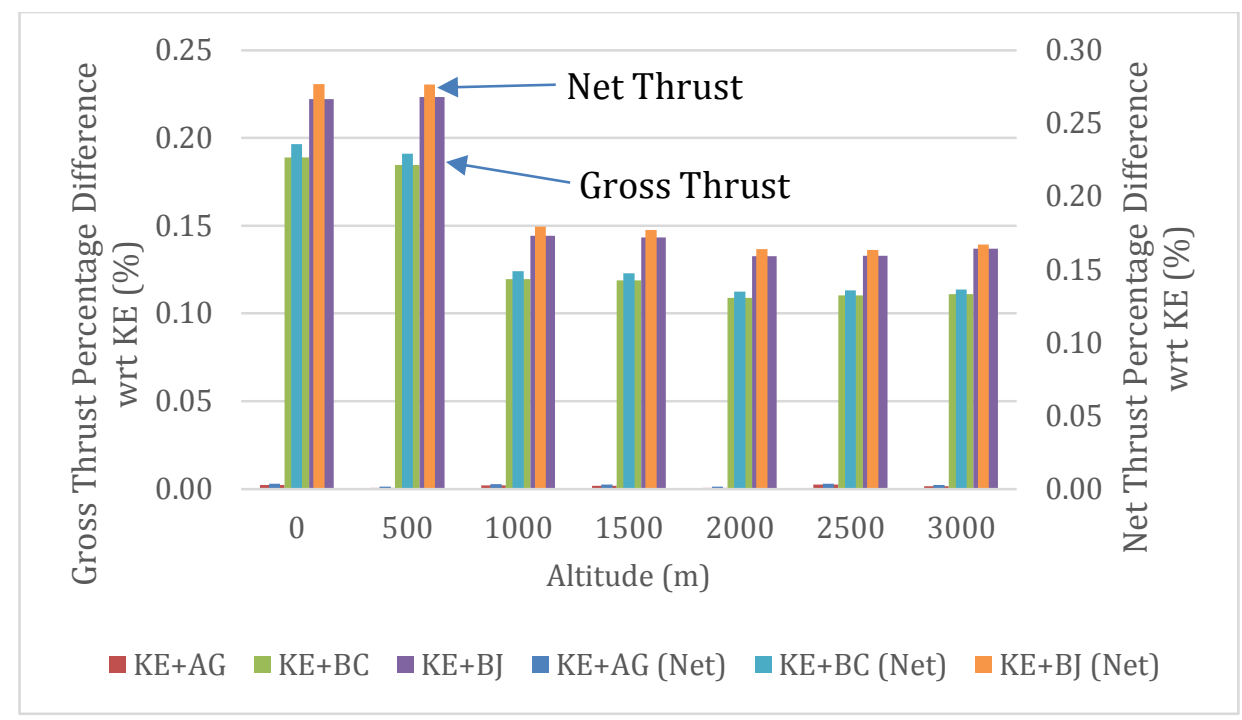

Figure 8. Gross and net thrusts percentage differences with respect to kerosene.

Fuel flow shows a negative linear variation at every altitude for all fuels (Figure 9). Likewise, the $50 \%$ of $\mathrm{KE}+\mathrm{BJ}$ and $50 \%$ of $\mathrm{KE}+\mathrm{BC}$ blended biofuels have a much lower fuel flow as compared to the baseline fuel. Meanwhile, $50 \%$ of KE+AG blended biofuel has an equivalent fuel flow as the baseline fuel and shows a constant percentage difference of fuel flow at different altitudes. Furthermore, only $50 \%$ of $\mathrm{KE}+\mathrm{AG}$ blended biofuel shows a percentage increase of $0.15 \%$ in fuel flow at all altitudes compared to the baseline fuel. Besides, $50 \%$ of $\mathrm{KE}+\mathrm{BJ}$ and $\mathrm{KE}+\mathrm{BC}$ blended biofuels have a reduction of fuel flow up to $1.12 \%$ and $0.82 \%$ respectively as shown in column graphs on the secondary axis.

The variations are much different and significant for the SFC. SFC is reduced at a high altitude (Figure 10). Only $50 \%$ of KE+AG blended biofuel shows a higher SFC than the baseline fuel. Nonetheless, $50 \%$ of $\mathrm{KE}+\mathrm{BJ}$ and $\mathrm{KE}+\mathrm{BC}$ blended biofuels have reduced percentages of SFC (up to $1.28 \%$ and $0.96 \%$ respectively) as compared to the baseline fuel. Meanwhile, $50 \%$ of KE+AG blended biofuel displayed an increment of $0.14 \%$ in SFC. These demonstrate that the $50 \%$ of $\mathrm{KE}+\mathrm{BJ}$ and $\mathrm{KE}+\mathrm{BC}$ blended biofuels have a much lower fuel flow and fuel consumption regardless of the changes in altitude. 


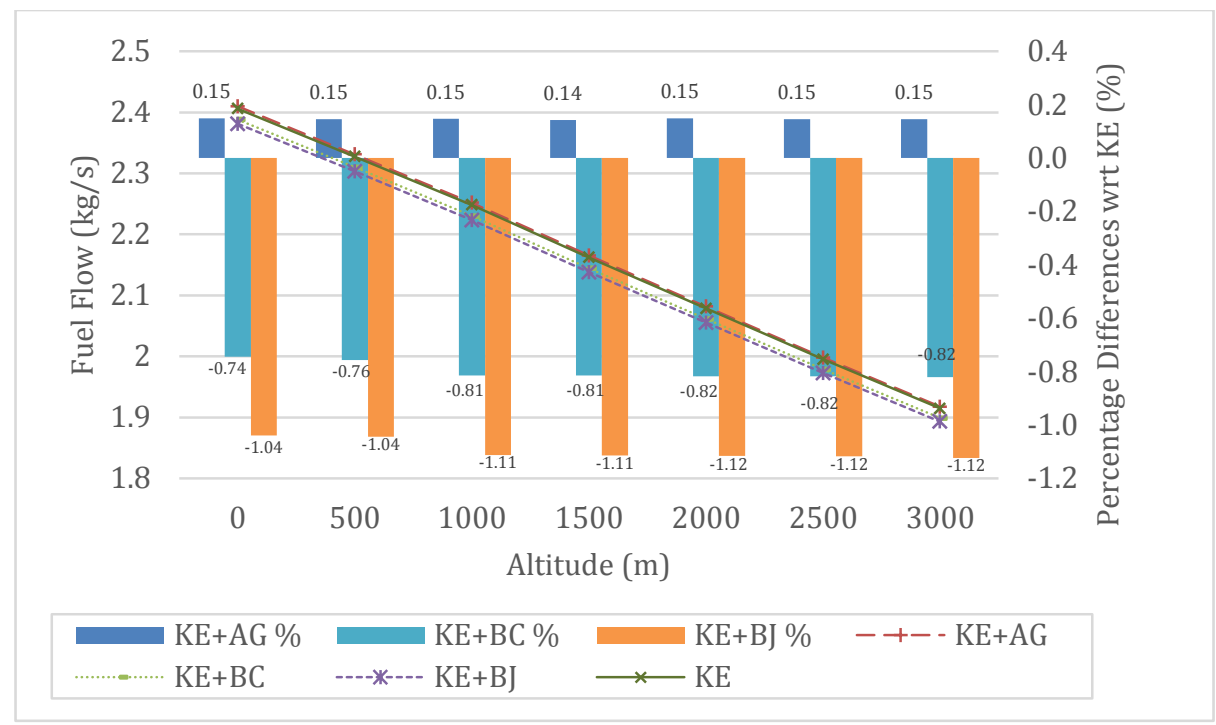

Figure 9. Variation of fuel flow at different altitudes.

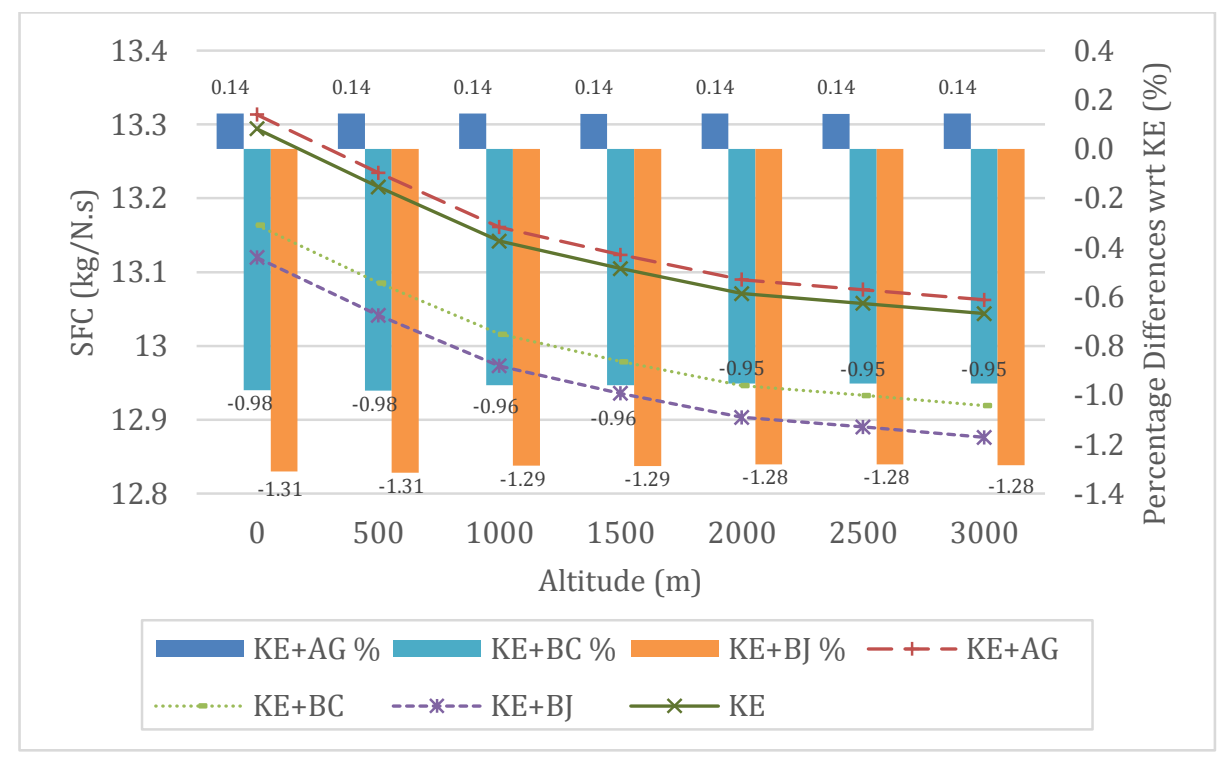

Figure 10. Variation of SFC at different altitudes.

\subsection{Influence of various mixing ratio blended fuel on aircraft engine performance at cruising condition}

This section discusses the effects of other blending mixing ratio percentages on engine performance at the cruising flight condition. The ambient and flight conditions are illustrated in Figure 11 which presents the gross thrust variation and percentage difference as compared to the baseline fuel. There is an increase in gross thrust for all fuel combinations. KE+BJ 
blended biofuel shows a much higher increase in gross thrust which is then followed by $\mathrm{KE}+\mathrm{BC}$ and $\mathrm{KE}+\mathrm{AG}$ blended biofuels. $\mathrm{BJ}$ pure biofuel (mixing ratio of 1 ) has a $0.23 \%$ increase in gross thrust while BC pure biofuel achieved an increase of $0.18 \%$. BJ pure biofuel has a $0.42 \%$ increase in net thrust while BC pure biofuel achieved an increase of $0.35 \%$. However, KE+AG blended biofuel has a very slight increase in both gross and net thrusts (by only up to $0.01 \%)$.

$\mathrm{KE}+\mathrm{BJ}$ and $\mathrm{KE}+\mathrm{BC}$ blended biofuels display a linear fuel flow reduction as mixing ratio percentage increases as depicted in Figure 12. Results show a reduction of $2.22 \%$ and $1.63 \%$ in the fuel flow for pure $\mathrm{BJ}$ and $\mathrm{BC}$ respectively. However, $\mathrm{KE}+\mathrm{AG}$ blended biofuel shows an increment in fuel flow at about $0.29 \%$ at higher mixing ratio percentages. Similarly, $\mathrm{KE}+\mathrm{BJ}$ and $\mathrm{KE}+\mathrm{BC}$ blended biofuels exhibit a reduction in SFC as the mixing ratio increases (Figure 13 ). SFC is reduced by up to $2.63 \%$ for the BJ pure biofuel while it is reduced by $1.96 \%$ for the BC pure biofuel. Besides, AG biofuel shows an increase of up to $0.28 \%$ on SFC in pure form. It should be noted that the use of BJ and BC can reduce the fuel flow and SFC for every percentage of blending ratio, but not for AG fuel.

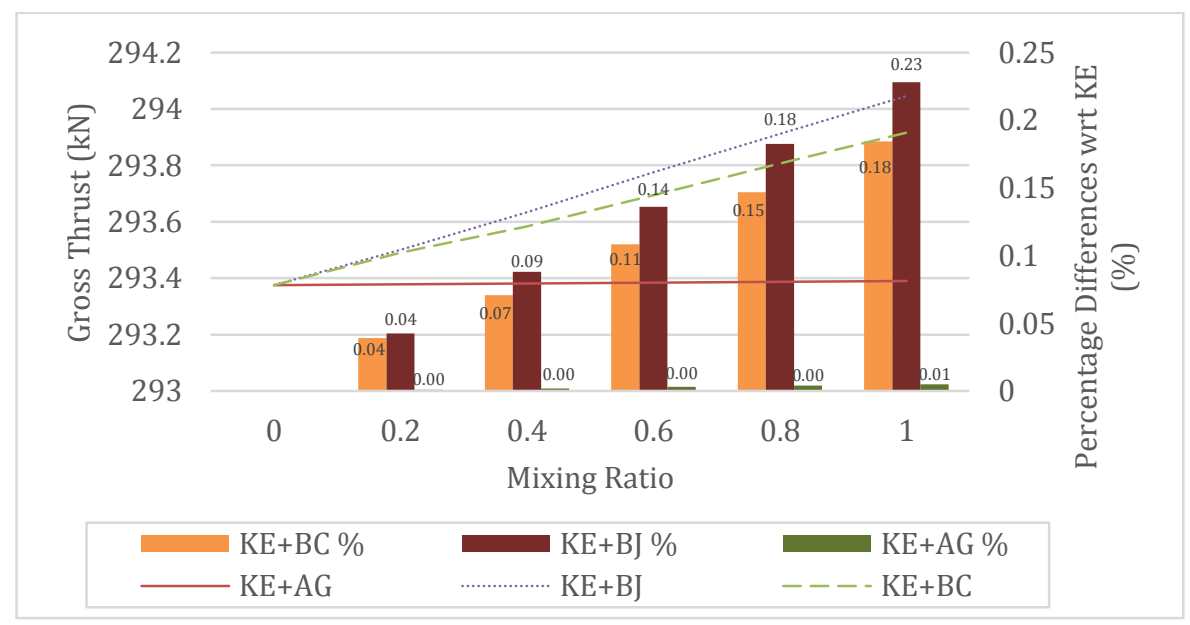

Figure 11. Variation of gross thrust at different mixing ratios. 


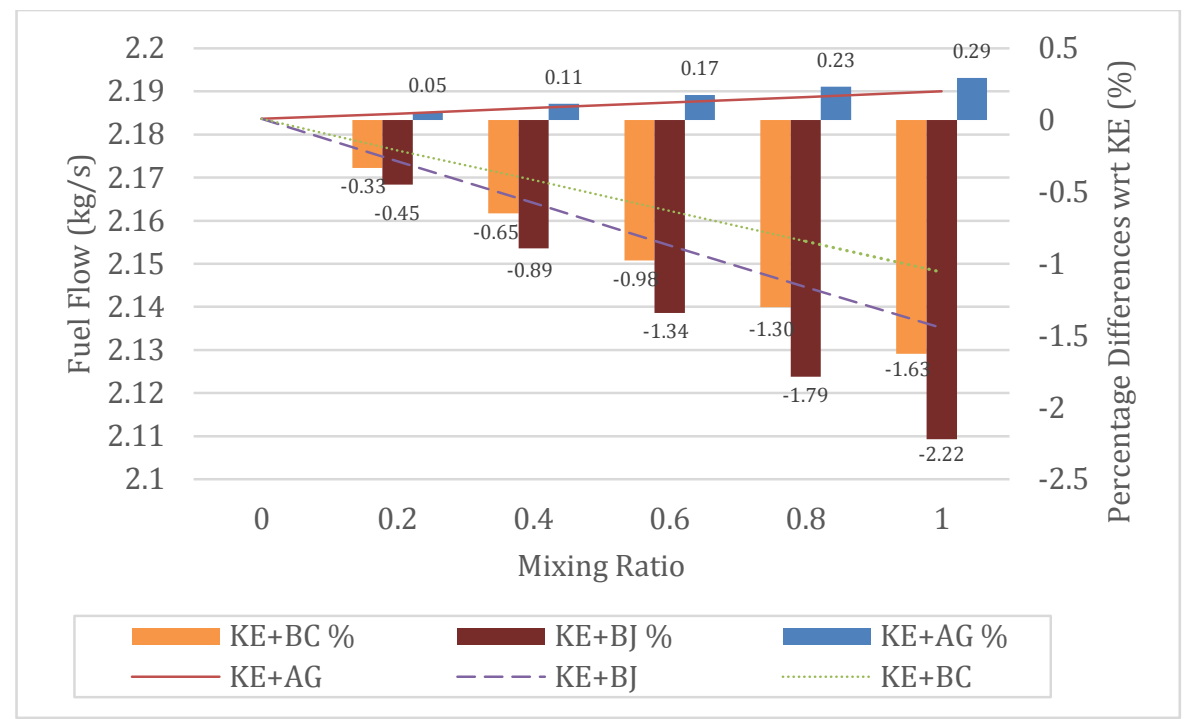

Figure 12. Variation of fuel flow at different mixing ratios.

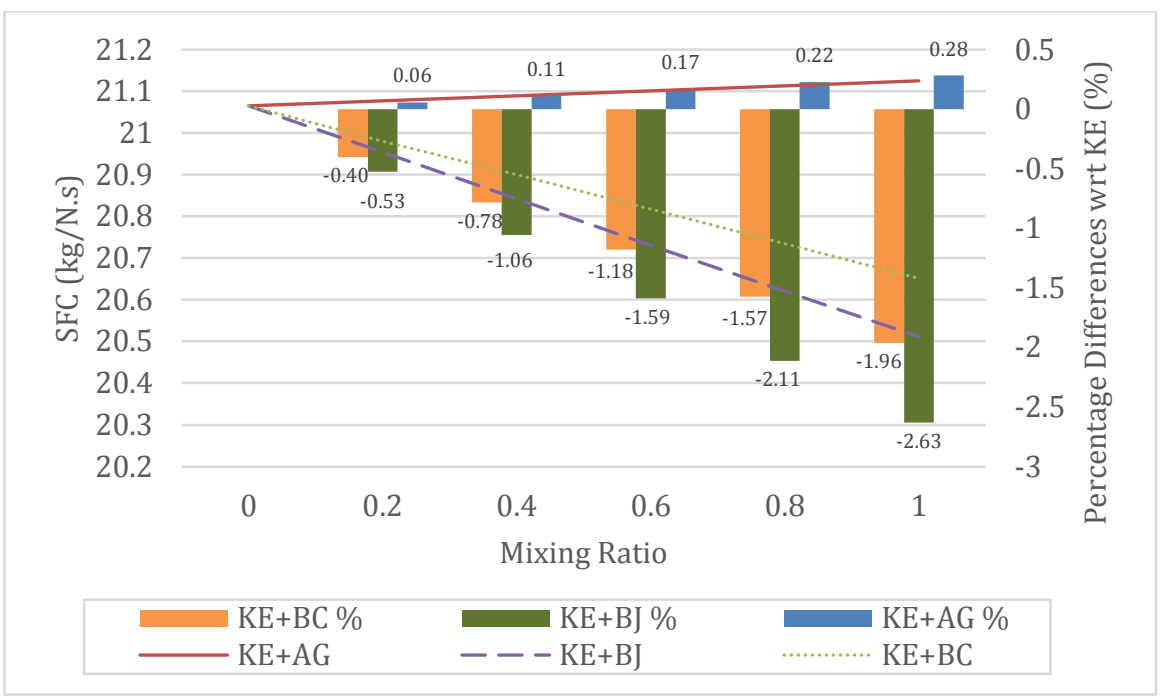

Figure 13. Variation of SFC at different mixing ratios.

As previously discussed, the performance of the aircraft engine can deliberately be enhanced by substituting kerosene fuel with pure alternative fuels. Thermochemical properties of the fuels distinguish the engine performance. These, however, should comply with the regulations enforced by the regulating tests and agencies. As alternative fuels are introduced into the combustor, some assumptions should be addressed. Firstly, combustion efficiency remained the same for all fuels because it may vary in atomization due to the differences in thermochemical properties. Secondly, the properties of alternative fuels used are taken from the published literature without taking consideration of ASTM approval and the fuel process 
methodology. Thirdly, combustor with different of blended fuels is our primary focus, thus, several results can be drawn due to the effect of changed thermochemical properties. It is observed that the total pressure, the mass flow and the pressure drop are increased slightly at higher percentage blended mixing ratio. As the total pressure and mass flow rise, the exit velocity is increased, resulting in an increase in gross thrust. However, the pressure drop in the combustor is increased as well. Furthermore, the fuel-to-air ratio (FAR) is reduced, indicating that more air is introduced to complete the burning. These explained more fuel flow reduction at higher mixing ratio blend. Although large LHV fuel provides a better propulsive performance, it will likely requires more air for combustion. Another crucial parameter is TIT as it determines the propulsive performance. Next, TIT was set to $1580 \mathrm{~K}$ for all cases. It is observed that high LHV fuel are able to sustain the temperature longer which is essentially important to expand and convert high energy to useful work and kinetic energy.

To compare objectively, Figure 14 and Figure 15 illustrate how these pure alternative fuels (AG, BC, and BJ) could enhance the performance at ground idle and cruising conditions. At ground idle, BJ and BC fuels give more thrust, reduce fuel flow and SFC as compared to kerosene fuel. AG fuel showcased a very slight increase in thrust, but also displayed an increase in fuel flow and SFC. However, at cruising condition, the percentage differences with the baseline kerosene fuel are reduced for BJ and BC fuels for the gross thrust. In contrary, AG fuel has a slight increment. Furthermore, fuel flow and SFC have been improved in cruising.

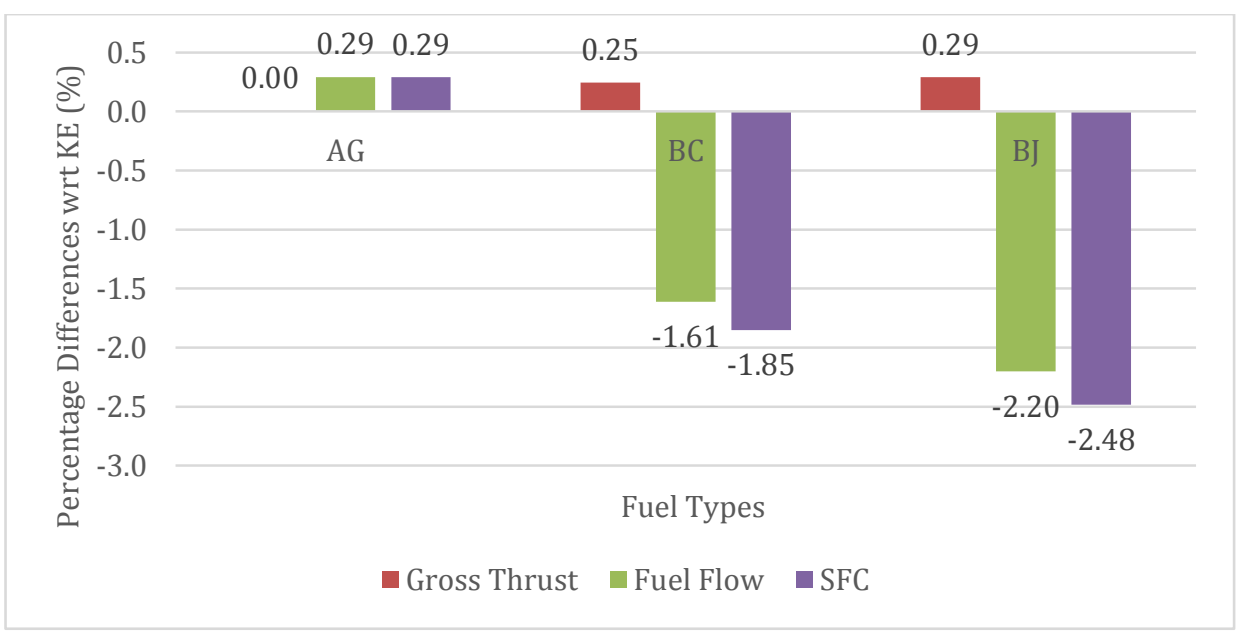

Figure 14. Performance comparison of pure alternative fuel at ground condition. 


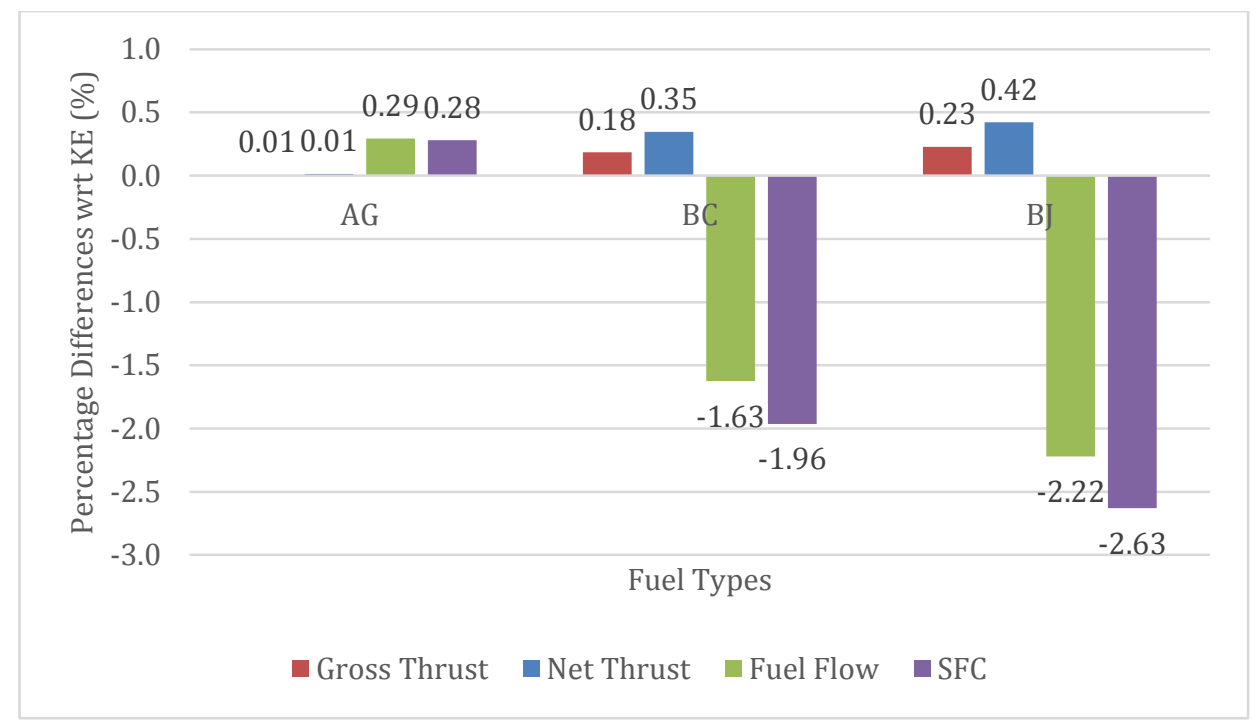

Figure 15. Performance comparison of pure alternative fuel at cruise condition.

\section{Conclusion}

Firstly, the results indicated that the LHV of the fuel had a significant influence on the engine performance metrics such as thrust, fuel flow, and SFC at every flight condition and at different blended mixing ratio percentages. The greater the LHV difference between two fuels, the larger the change in the engine performance. Secondly, the performance analysis of $50 \%$ blended alternative biofuels is discussed thoroughly at two flight conditions which are takeoff (varying flight speed) and climbing (varying altitude). 50\% blended alternative biofuels are commonly used for flight-testing within the existing engine specifications. $50 \%$ of $\mathrm{KE}+\mathrm{BJ}$ and $\mathrm{KE}+\mathrm{BC}$ blended biofuel reported an increase in gross thrust and net thrust as well as improvements in fuel flow and SFC at a higher flight speed as compared to the baseline fuel. However, $50 \%$ of $\mathrm{KE}+\mathrm{AG}$ blended biofuel showed no significant changes in gross and net thrusts but an increase in fuel flow and SFC. At climbing conditions however, both $50 \%$ of $\mathrm{KE}+\mathrm{BJ}$ and $\mathrm{KE}+\mathrm{BC}$ blended biofuels showed increment in gross and net thrusts and much more reductions in fuel flow and SFC as compared to the baseline fuel. On the other hand, $50 \%$ of $\mathrm{KE}+\mathrm{AG}$ blended biofuel displayed a much higher fuel flow and SFC than the baseline fuel. 
Thirdly, the influence of various percentage mixing ratios is discussed at cruising condition. $\mathrm{KE}+\mathrm{BJ}$ and $\mathrm{KE}+\mathrm{BC}$ fuels again presented a much better engine performance as compared to the $K E+A G$ fuel as the mixing ratio percentages increase. $K E+B J$ surpassed $K E+B C$ in term of all engine performance metrics. However, KE+AG fuel has resulted in an increase in both fuel flow and SFC. Apparently, all pure biofuels (AG, BC, and BJ) appeared to offer slight improvements on gross thrust. However, only BJ and BC fuels showed reductions in fuel flow and SFC. Pure alternative fuels for both ground and cruising conditions were evaluated. At these different conditions, AG fuel has resulted in a slight increase in gross thrust at cruise, while BJ and BC fuels showed slight reductions as compared to ground condition. Nevertheless, fuel flow and SFC have shown much improvement for BJ and BC fuels at cruising condition.

\section{Acknowledgments}

The lead author would like to acknowledge and to thank International Islamic University Malaysia, Malaysia for the sponsoring his $\mathrm{PhD}$ research work.

\section{References}

1. Amin S. Review on biofuel oil and gas production processes from microalgae. Energy Convers Manag [Internet]. Elsevier Ltd; 2009 Jul [cited 2014 Jul 9];50(7):1834-40. Available from: http://linkinghub.elsevier.com/retrieve/pii/S0196890409000764

2. Azami MH, Savill M. Modelling of spray evaporation and penetration for alternative fuels. FUEL [Internet]. Elsevier Ltd; 2016;180:514-20. Available from: http://dx.doi.org/10.1016/j.fuel.2016.04.050

3. Hoekman SK, Broch A, Robbins C, Ceniceros E, Natarajan M. Review of biodiesel composition, properties, and specifications. Renew Sustain Energy Rev [Internet]. Elsevier Ltd; 2012;16(1):143-69. Available from: http://dx.doi.org/10.1016/j.rser.2011.07.143

4. Ashraful AM, Masjuki HH, Kalam MA, Fattah IMR, Imtenan S, Shahir SA, et al. Production and comparison of fuel properties, engine performance, and emission characteristics of biodiesel from various non-edible vegetable oils : A review. Energy 
Convers Manag [Internet]. Elsevier Ltd; 2014;80:202-28. Available from:

http://dx.doi.org/10.1016/j.enconman.2014.01.037

5. Atabani AE, Silitonga AS, Badruddin IA, Mahlia TMI, Masjuki HH, Mekhilef S. A comprehensive review on biodiesel as an alternative energy resource and its characteristics. Renew Sustain Energy Rev [Internet]. Elsevier Ltd; 2012 May [cited 2014 Jul 17];16(4):2070-93. Available from: http://linkinghub.elsevier.com/retrieve/pii/S1364032112000044

6. Maity JP, Bundschuh J, Chen C-Y, Bhattacharya P. Microalgae for third generation biofuel production, mitigation of greenhouse gas emissions and wastewater treatment: Present and future perspectives - A mini review. Energy [Internet]. Elsevier Ltd; 2014 Apr [cited 2014 Aug 22]; Available from: http://linkinghub.elsevier.com/retrieve/pii/S0360544214004150

7. Fortier M-OP, Roberts GW, Stagg-Williams SM, Sturm BSM. Life cycle assessment of bio-jet fuel from hydrothermal liquefaction of microalgae. Appl Energy [Internet]. Elsevier Ltd; 2014 Jun [cited 2014 Jul 18];122(July 2011):73-82. Available from: http://linkinghub.elsevier.com/retrieve/pii/S030626191400107X

8. Payan AP, Kirby M, Justin CY, Mavris DN. Meeting Emissions Reduction Targets : A Probabilistic Lifecycle Assessment of the Production of Alternative Jet Fuels. In: AIAA/3AF Aircraft Noise and Emissions Reduction Symposium. Atlanta, GA: American Institute of Aeronautics and Astronautics; 2014. p. 1-17.

9. Giakoumis EG, Rakopoulos CD, Dimaratos AM, Rakopoulos DC. Exhaust emissions of diesel engines operating under transient conditions with biodiesel fuel blends. Prog Energy Combust Sci [Internet]. Elsevier Ltd; 2012;38(5):691-715. Available from: http://dx.doi.org/10.1016/j.pecs.2012.05.002

10. Padmanabhan MR A, Stanley SA. Microalgae as an Oil Producer for Biofuel Applications. Res J Recent Sci. 2012;1(3):57-62.

11. Singh J, Gu S. Commercialization potential of microalgae for biofuels production. Renew Sustain Energy Rev [Internet]. Elsevier Ltd; 2010 Dec [cited 2014 Jul 10];14(9):2596-610. Available from: http://linkinghub.elsevier.com/retrieve/pii/S1364032110001619 
12. Rahmes TF, Kinder JD, Henry TM, Crenfedlt G, LeDuc GF, Zombanakis GP, et al. Sustainable Bio-Derived Synthetic Paraffinic Kerosene (Bio- SPK) Jet Fuel Flights and Engine Tests Program Results. In: 9th AIAA Aviation Technology, Integration, and Operations Conference (ATIO). Hilton Head, South Carolina: American Institute of Aeronautics and Astronautics; 2009. p. 1-19.

13. Igie U, Minervino O. Impact of Inlet Filter Pressure Loss on Single and Two-Spool Gas Turbine Engines for Different Control Modes. J Eng Gas Turbines Power [Internet]. 2014;136(9):091201. Available from: http://www.scopus.com/inward/record.url?eid=2s2.0-84900036199\&partnerID=tZOtx3y1

14. Mazlan NM, Savill M, Kipouros T. Effects of biofuels properties on aircraft engine performance. Aircr Eng Aerosp Technol [Internet]. 2015;87:437-42. Available from: http://www.emeraldinsight.com/doi/10.1108/AEAT-09-2013-0166

15. Li YG, Ghafir MFA, Wang L, Singh R, Huang K, Feng X. Nonlinear Multiple Points Gas Turbine Off-Design Performance Adaptation Using a Genetic Algorithm. J Eng Gas Turbines Power. 2011;133(July 2011):1-9.

16. Li YG, Abdul Ghafir MF, Wang L, Singh R, Huang K, Feng X, et al. Improved Multiple Point Nonlinear Genetic Algorithm Based Performance Adaptation Using Least Square Method. J Eng Gas Turbines Power [Internet]. 2012;134(3):1 - . Available from: http://gasturbinespower.asmedigitalcollection.asme.org/article.aspx?articleid=1429782

17. Alcaine AA. Biodiesel from microalgae [Internet]. Biotechnology Advances. 2007. Available from:

http://www.sciencedirect.com/science/article/pii/S0734975007000262 Inhttp://www.scie ncedirect.com/science?_ob=ShoppingCartURL\&_method=add\&_eid=1-s2.0S0734975007000262\&originContentFamily=serial\&_origin=article\&_acct=C00022859 8\&_version $=1 \& \_$userid $=10 \& \_t s=1328202370 \& \mathrm{md} 5=\mathrm{f} 917 \mathrm{a} 2 \mathrm{bd} 328 \mathrm{cebe} 6 \mathrm{a} 906282 \mathrm{f} 938 \mathrm{f}$ $12 \mathrm{ce}$

18. Haik Y, Selim MYE, Abdulrehman T. Combustion of algae oil methyl ester in an indirect injection diesel engine. Energy [Internet]. Elsevier Ltd; 2011 Mar [cited 2014 Nov 17];36(3):1827-35. Available from: http://linkinghub.elsevier.com/retrieve/pii/S0360544210006432 
19. Jena U, Vaidyanathan N, Chinnasamy S, Das KC. Evaluation of microalgae cultivation using recovered aqueous co-product from thermochemical liquefaction of algal biomass. Bioresour Technol [Internet]. Elsevier Ltd; 2011;102(3):3380-7. Available from: http://dx.doi.org/10.1016/j.biortech.2010.09.111

20. Makarevičienè V, Lebedevas S, Rapalis P, Gumbyte M, Skorupskaite V, Žaglinskis J. Performance and emission characteristics of diesel fuel containing microalgae oil methyl esters. Fuel [Internet]. 2014 Mar [cited 2014 Nov 17];120:233-9. Available from: http://linkinghub.elsevier.com/retrieve/pii/S0016236113011204

21. Rinaldini CA, Mattarelli E, Magri M, Beraldi M. Experimental Investigation on Biodiesel from Microalgae as Fuel for Diesel Engines. SAE Tech Pap. 2014;

22. Giakoumis EG. A statistical investigation of biodiesel physical and chemical properties , and their correlation with the degree of unsaturation. Renew Energy [Internet]. Elsevier Ltd; 2013;50:858-78. Available from: http://dx.doi.org/10.1016/j.renene.2012.07.040

\section{Nomenclature}

$A G$

$\mathrm{BC}$

BJ

BPR

CFPP

ETA

FAR

KE

LHV

NGV

$\mathrm{P}$

$P_{n}$

PR

SFC
Algae Biofuel

Camelina Biofuel

Jatropha Biofuel

By-pass Ratio

Cold Filter Plugging Point

Efficiency

Fuel-to-air Ratio

Kerosene

Lower Heating Value

Nozzle Guide Vane

Pressure

Pressure at $n$-stage

Pressure Ratio

Specific Fuel Consumption 
$\mathrm{T}$

$T_{n}$

$v_{a}$

WA

$W_{n}$

Z

Greek

$\eta_{P}$

$\eta_{T}$
Temperature

Temperature at n-stage

Flight Approaching Speed

Mass Flow

Mass Flow at n-stage

Surge Margin Parameter

Propulsive Efficiency

Thermodynamic Efficiency 
2016-07-22

\section{Comparative study of alternative biofuels on aircraft engine performance}

Azami, M. H.

Sage

Azami, M. H., Savill, M. (2016) Comparative study of alternative biofuels on aircraft engine performance, Proceedings of the Institution of Mechanical Engineers, Part G: Journal of Aerospace Engineering, Vol. 231, Issue 8, 2017, pp. 1509-1521

http://dx.doi.org/10.1177/0954410016654506

Downloaded from Cranfield Library Services E-Repository 